\title{
Towards Covid-19 Literacy
}

\section{Investigating the Literacy Levels of University Students in Colombia}

\author{
Pablo Antonio Archila ${ }^{1}$ (D) . Giovanna Danies ${ }^{2}$. Jorge Molina ${ }^{3}$. \\ Anne-Marie Truscott de Mejía ${ }^{4}$. Silvia Restrepo ${ }^{1}$
}

Accepted: 25 March 2021 / Published online: 19 April 2021

(c) The Author(s), under exclusive licence to Springer Nature B.V. 2021

\begin{abstract}
Covid-19 literacy, induced by the coronavirus disease (2019), is characterized as the understanding of Covid-19 as well as informed decisions based upon this understanding. This type of literacy is closely related to health literacy, scientific literacy, and scientific media literacy. It may be obvious to say that Covid-19 literacy is a key factor for governments to effectively manage the Covid-19 transition. However, lack of literature exists about Covid19 literacy among university students. Therefore, the current study aimed to determine the Covid-19 literacy level among 4168 students from a Colombian university. The data were derived from students' responses to a 25-item anonymous online self-reporting questionnaire. We found that 21-25-year age group, graduate students, students enrolled prior to 2015, and medical students had a significantly higher mean score. Moreover, the Internet $(86.8 \%)$ was the most popular source of information from which participants gained most information regarding Covid-19. Furthermore, 58.5\% of the participants considered health workers as a source that can provide accurate information. Most importantly, the findings reveal the students' knowledge about (1) the role of an eventual process of vaccination, (2) the test currently used as diagnostic for Covid-19, and (3) the fatality rate, three aspects of Covid-19 literacy that deserve more attention. The findings provide a useful basis for the formulation of policies and concrete actions in improving Covid-19 literacy.
\end{abstract}

Keywords Covid-19 $\cdot$ Health literacy $\cdot$ Pandemic $\cdot$ Scientific literacy $\cdot$ Scientific media literacy

\section{Introduction}

According to Archila et al. (2020a), puerperal fever, which was endemic in the nineteenth century, is just one of the multiple diseases where there is a lesson to be learned (e.g., regular and rigorous handwashing) which can be useful in times of the Covid-19 pandemic. Moreover, humanity has battled with and managed to recover from similar severe diseases in the past (Reiss, 2020; Yamin, 2020). In this respect, several scholars argue that coronavirus

Pablo Antonio Archila

pa.archila@uniandes.edu.co

Extended author information available on the last page of the article 
disease (2019) induced Covid-19 literacy, which can be characterized as the understanding of Covid-19 and making informed decisions based upon this understanding, is a key factor required for the successful control of the Covid-19 pandemic (Anju \& Arulsamy, 2020; Hamza et al., 2021; Nguyen et al., 2020; Seale et al., 2020). In particular, there are three problematic issues in which Covid-19 literacy is vital. Firstly, the Covid-19 crisis has resulted in Covid-19 infodemic which is defined as the availability of an overwhelming amount of both accurate and inaccurate information related to Covid-19 (Habersaat et al., 2020; Saribas $\&$ Çetinkaya, 2020; Sentell et al., 2020). Secondly, the rapid and far-reaching spread of both trustworthy and untrustworthy academic papers about this pandemic has led to a Covid-19 paperdemic (Dinis-Oliveira, 2020; Palayew et al. 2020). Thirdly, the anti-vaccine movement causes both the infodemic and the paperdemic to spread anti-vaccine (mis)information (Ball \& Maxmen, 2020; Kearns \& Kearns, 2020; Saribas \& Çetinkaya, 2020).

Given these problematic issues, it is plausible to consider that Covid-19 literacy is intimately related to scientific media literacy - thinking critically about the scientific information received through the media and its critical use, weighing claims against the scientific evidence (Archila et al., 2019, a, b, c); health literacy-"the achievement of a level of knowledge, personal skills, and confidence to take action to improve personal and community health by changing personal lifestyles and living conditions" (World Health Organization, 1998, p. 10); and scientific literacy-understanding of science and making informed decisions based upon this understanding (Roberts, 2007). It is not surprising that Habersaat et al. (2020) have included these aspects in the group of key considerations for governments to effectively manage the Covid-19 transition.

Thorp (2020) asserts that the scientific community is losing the battle against digital misinformation in times of the Covid-19 pandemic. Additionally, Verma et al. (2020) note that identifying reliable news sources has become as important as finding ways to avoid infection from the severe acute respiratory syndrome coronavirus 2 (SARS-CoV-2). Clearly, science education can contribute to the promotion of Covid-19 literacy. Erduran (2020a), for example, highlights the importance of exploring educational ways to equip citizens with scientific skills (e.g., scientific argumentation) to understand and to cope with this pandemic.

Since the uncertain effects of the Covid-19 pandemic can last for a long time (Erduran, 2020a) and there is not yet enough research investigating Covid-19 literacy levels, it is important to study this type of literacy. In response to the need to take steps to move towards the promotion of Covid-19 literacy, we are particularly interested in the Covid-19 literacy level of university students in Colombia, for two reasons. First, Covid-19 literacy levels are a key factor to be considered in their influence on university students' willingness to abide by control measures (e.g., hygiene and social physical distancing) and to adopt critical attitudes towards Covid-19 infodemic and Covid-19 paperdemic in the pandemic and post-Pandemic eras (Gallè et al., 2020). And second, the lack of literature addressing Covid-19 literacy in university education is more marked in Latin American countries. Therefore, our study aims to provide baseline information for the development of effective educational strategies necessary for promoting a Covid-19 literate society. Specifically, this article seeks answers to the following two research questions:

(1) What is Colombian university students' level of Covid-19 literacy?

(2) How is student Covid-19 literacy level related to demographic variables, namely, gender, age, level of academic accomplishment (undergraduate or graduate), year of entry to the university $(<2015,2015-2016,2017-2018,2019-2020)$, and education major (e.g., economics, law, sciences)? 


\section{Conceptual Framework}

Having presented in Section 1 the definitions of the major components of Covid-19 literacy (health literacy, scientific literacy, and scientific media literacy), in this section, we discuss the conceptual framework of the main characteristics (transmission, clinical symptoms, treatment, and prevention) of Covid-19 as well as the benefits of Covid-19 literacy (Fig. 1). It is important to clarify that we define Covid-19 literacy as the functional understanding of Covid-19 as well as making informed decisions based upon this understanding. The functional understanding of Covid-19 refers to the development of knowledge of this disease that allows citizens to make sense of its main characteristics. Thus, the first part of this section addresses these characteristics, while the second deals with the role (benefits) of Covid-19 literacy in the pandemic and postpandemic times.

\subsection{Characteristic Features of Covid-19}

It is important to clarify that many unanswered questions about Covid-19 remain and more information about the main features of this virus are currently being studied. Hence, it should be kept in mind that the information presented in this section corresponds to that relating to the timing of the implementation of our study (9 to 20 November 2020). Here, we briefly discuss the main characteristics (transmission, clinical symptoms, treatment, prevention) of Covid-19 that can lead to Covid-19 literacy.

On December 31, 2019, the Chinese Center for Disease Control reported a cluster of severe pneumonia cases of unknown cause in the city of Wuhan, Hubei Province, in central China. About one month later (January 30, 2020), the World Health Organization (WHO) "declared the outbreak to be a public health emergency of international concern" (WHO, 2020a, p. 1). Moreover, about six weeks later (March 11, 2020), this

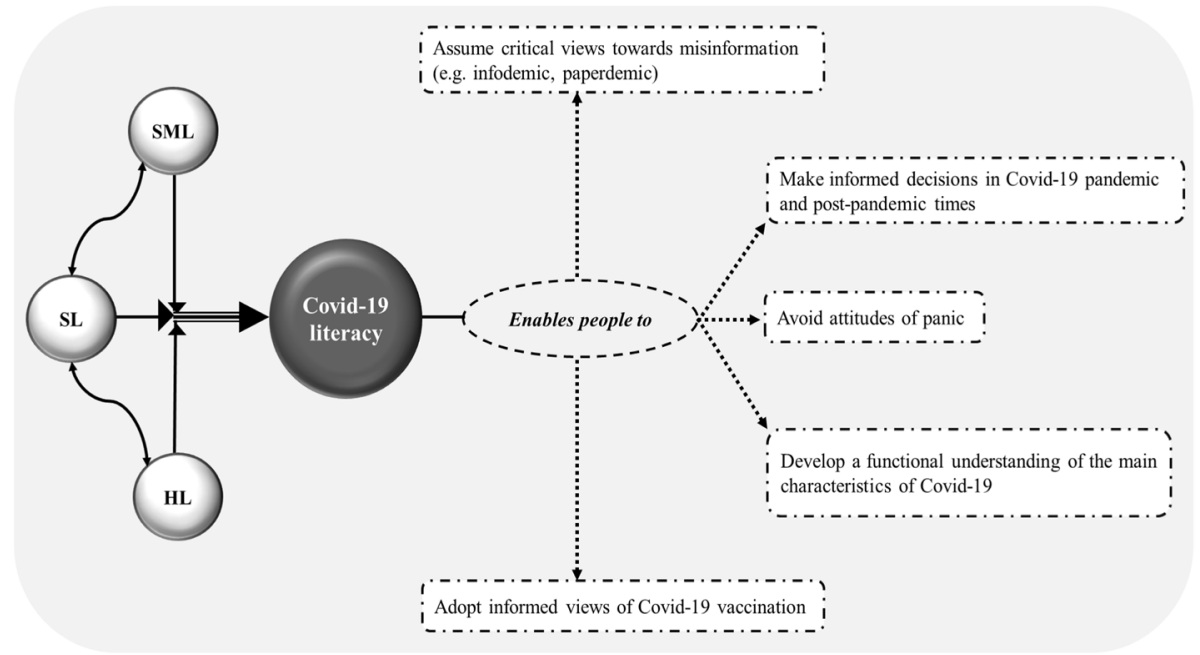

Fig. 1 Major components of Covid-19 literacy and its benefits. SML scientific media literacy, $S L$ scientific literacy, $H L$ health literacy 
organization declared Covid-19 to be a pandemic because of the continual rise in the number of affected countries, cases, and fatalities (WHO, 2020b).

With respect to transmission of Covid-19, WHO (2020c) has stressed the highly contagious and the life-threatening character of Covid-19. Its basic reproductive number $\left(R_{0}\right)$ - "an epidemiologic metric used to describe the contagiousness or transmissibility of infectious agents" (Delamater et al., 2019, p. 1) -is estimated by the WHO (2020d) "to range between 2 and 2.5, which is higher than that for SARS (1.7-1.9) and MERS (<1)" (Petrosillo et al., 2020, p. 730). WHO (2020e) has stated that SARSCoV-2 is transmitted with high efficacy and infectivity mainly through contact (e.g., fomite transmission) and respiratory routes. Also, this organization and Prather et al. (2020) have stressed that aerosols may represent another important route. A key aspect here is that the virus is predominantly spread from person-to-person through infected secretions (e.g., saliva) and respiratory secretions or respiratory droplets.

Clinical symptoms of Covid-19 are another relevant characteristic feature of this disease. According to Lauer et al. (2020), the median incubation period for SARSCoV-2 has been estimated to be 5.1 days. Moreover, they assert that $97.5 \%$ of people who develop symptoms will do so within 11.5 days of infection. Clinical symptoms begin gradually and about $80 \%$ of patients have mild symptoms. WHO (2020f) has listed some of them: aches and pains, a skin rash, conjunctivitis, diarrhea, discoloration of fingers or toes, a dry cough, fever, headache, loss of taste or smell, nasal congestion, sore throat, and tiredness. At this point, it is relevant to emphasize that infected people may be asymptomatic. In addition, coexistent conditions and old age (60 years of age or older) have been identified as potential risk factors for severe disease (Li et al., 2020a, 2020b, 2020c).

With reference to treatment for Covid-19, Ciotti et al. (2020) mention that there is no approved antiviral curative treatment for this disease even if a patient is classified as an asymptomatic, suspected, mild or severe ill case. The polymerase chain reaction (PCR) test is currently used as diagnostic for Covid-19 (Miller et al. 2020; Weissleder et al. 2020). Care for patients is primarily supportive. Case detection and isolation ( $\sim 14$ days) are two of the multiple actions adopted by several governments. It is important to note that SARS-CoV-2 can be fatal in $\sim 3 \%$ of cases. This suggests that this virus seems to be less pathogenic than SARS-CoV-1 ( 10\%), and much less than the Middle East respiratory syndrome coronavirus (MERS-CoV) ( 40\%) (Chen, 2020).

Finally, some information related to prevention of Covid-19 transmission should be mentioned. Early, planned, purposeful, and systematic intervention in the spread of SARS-CoV-2 is fundamental to be able to break the transmission and spread of Covid19. Everyday preventative actions include the following: appropriate face hygiene (avoid touching eyes, nose, and mouth), frequent cleaning and disinfection of objects and surfaces which have been touched, regular, and rigorous handwashing (for at least 40-60 s), respiratory etiquette (covering mouth and nose while coughing or sneezing), social distancing (e.g., maintaining a physical distance of 1.5-2.0 m between people), staying at home when sick, use of face mask, and (voluntary) home quarantine (Centers for Disease Control \& Prevention, 2020; Ciotti et al., 2020).

\subsection{The Role of Covid-19 Literacy in the Pandemic and Post-Pandemic Eras}

We consider that Covid-19 literate individuals are able to (1) assume a critical posture towards the Covid-19 information they find in the media (Ball \& Maxmen, 2020; 
Dinis-Oliveira, 2020; Erduran, 2020b; Paakkari \& Okan, 2020); (2) develop a functional understanding of this disease (Erduran, 2020b; Gallè et al., 2020; Kotian et al. 2020); (3) adopt informed and critical views of the multiple interests (not only scientific) behind vaccination (Dinis-Oliveira, 2020); (4) avoid panic attitudes (Abdel-Latif, 2020; Habersaat et al., 2020; Nguyen et al., 2020); and (5) make informed decisions in Covid-19 pandemic and post-pandemic times (Alahdal et al. 2020).

In this section, we will now discuss the role of Covid-19 literacy in the pandemic and post-pandemic eras. In particular, we synthesized five reasons from several literature sources to support the claim that Covid-19 literacy is an important aspect in dealing with the Covid-19 pandemic (Fig. 1). The first reason emerges after recognizing that this pandemic is accompanied by Covid-19 infodemic and Covid-19 paperdemic (Ball \& Maxmen, 2020; Dinis-Oliveira, 2020; Saribas \& Çetinkaya, 2020). Erduran (2020b) points out that sometimes media channels expose the public to numerous accounts of fallacious reasoning related to Covid-19 (e.g., astonishing myths about curing Covid19 patients). Fallacious reasoning is one of the various strategies used by Covid-19 infodemic and Covid-19 paperdemic promoters to manipulate people to start taking unproven medication and/or to refuse a vaccine (Ball \& Maxmen, 2020). Clearly, if citizens are unaware of Covid-19, this facilitates belief in fallacious reasoning which can have devastating effects on the desirable control of this pandemic (Murillo-Llorente \& Perez-Bermejo, 2020).

The need to have a functional understanding of Covid-19 is the second reason to consider Covid-19 literacy as a vital aspect in the midst of this pandemic (Erduran, 2020b; Gallè et al., 2020; Kotian et al., 2020). It is not enough for people merely to adopt some preventive protocols (e.g., handwashing, wearing masks), they also need to develop a functional understanding of Covid-19. This functional understanding is fundamental in creating interdependence-citizens feeling committed to one another and the success of one citizen in containing this pandemic being seen as dependent on others-and helping citizens to become aware of SARS-CoV-2 (Alahdal et al. 2020).

The third reason is that Covid-19 literacy can contribute to the promotion of informed and critical views of vaccination. In 1909, Sinclair (1909) considered Semmelweis's (1 July 1818-13 August 1865) introduction of antisepsis and Edward Jenner's (17 May 1749-26 January 1823) introduction of vaccination as the two most relevant discoveries in producing direct and immediate blessings to humanity due to the saving of life and the prevention of suffering. Interestingly, more than a hundred years later, vaccination is a topic of controversy. This is a point that deserves critical reflection whether we recognize that vaccination is tentatively considered to be a key resource for Covid19 control. In line with this, Covid-19 literacy can help empower citizens so that they adopt scientific habits of mind that help them become aware of the general aspects (e.g., experimental evidence, tentativeness, uncertainty) behind the development of Covid-19 vaccines.

The fourth reason is that Covid-19 literacy can protect people from "fear of Covid19" (Nguyen et al., 2020, p. 1). According to Abdel-Latif (2020) and Nguyen et al. (2020), naïve and uncritical exposure to misinformation relating to the Covid-19 pandemic exacerbates fear and panic among the public. Likewise, Habersaat et al. (2020) emphasize the fact that false and/or inaccurate information about the pandemic can cause stress and anxiety. It is hard to imagine that citizens would be able to make informed decisions when they are fearful. In other words, misleading information (e.g., false and/or inaccurate information) about this health crisis is mainly produced and shared to create panic, and this thus, generates the perfect scenario (fear-stress-anxiety) 
to manipulate the decisions of Covid-19 illiterate people. The situation is even more challenging than it seems because Covid-19 infodemic and Covid-19 paperdemic would probably continue in the post-pandemic era.

The need to prepare people to make informed decisions in Covid-19 pandemic and postpandemic times is the fifth reason to pay more attention to Covid-19 literacy (Alahdal et al. 2020; Zhu \& Liu, 2020). A first point to mention here is that making informed decisions is not only an aspect of scientific literacy (and of course of Covid-19 literacy) but also a key factor required for the successful control of the Covid-19 pandemic. Some of the decisions people are expected to make include the adoption (or not) of preventive protocols (e.g., wearing masks), administration (or not) of Covid-19 vaccines, and return (on not) to faceto-face activities (e.g., education, job). A second point is that the ability to make informed decisions about Covid-19 literacy may be a determinant of success in guiding people to adapting to all kinds of changes that the world will experience after the pandemic. Most importantly, this ability is essential because as Alahdal et al. (2020) argue, societies should be better prepared for epidemics that might occur in the future.

\section{Previous Studies as an Attempt to Measure Aspects of Covid-19 Literacy}

It is important to clarify that in this study we adopted a cross-sectional design. One reason for this is that this type of design involves the collection of data on more than one case and at a single point in time or over a short period. Another reason is that these data are usually collected in connection with two or more variables, which are then analyzed to detect patterns of association (Bryman, 2016). This largely explains why online cross-sectional surveys are the instruments most used in previous studies that have examined some aspects of Covid-19 literacy. These have focused on two types of subjects, namely (1) people in general and (2) particular groups, such as healthcare workers (e.g., Abdel Wahed et al., 2020, Olum et al., 2020), medical imaging professionals (Kotian et al., 2020), rural market vendors (e.g., Usman et al., 2020), and university students and staff (e.g., Salman et al. 2020). It is important to clarify that previous studies have focused mainly on the general public. These studies have been conducted in countries, such as Australia (Seale et al. 2020), China (Zhong et al. 2020), Egypt (Abdelhafiz et al. 2020), India (Anju \& Arulsamy, 2020), Indonesia (Sari et al., 2021), Iran (Honarvar et al., 2020), Nigeria (Reuben et al., 2020), Pakistan (Hayat et al., 2020), Saudi Arabia (Alahdal et al., 2020), Sudan (Mousa et al., 2020), and the USA (Clements, 2020; Li et al., 2020a, 2020b, 2020c).

An interesting result of the studies carried out in Australia $(N=1420$ Australian adults) (Seale et al. 2020) and Egypt ( $N=559$ Egyptian adults) (Abdelhafiz et al. 2020) was that $51 \%$ and $52.6 \%$ of the participants, respectively, mentioned that television (TV) was one of their main sources of information about the Covid-19 crisis. This contrasts considerably with the $27.5 \%$ reported in Nigeria $(N=589$ Nigerian residents $)$ (Reuben et al. 2020). This is a key result because it demonstrates that it is not possible to generalize the sources of information from which the general population gains most information regarding the Covid-19 pandemic. Therefore, contextual factors (variables) of each community should be carefully considered when examining sources of information, such as TV.

Having clarified that previous studies have focused mainly on the general population, in the following paragraphs, we discuss the case of previous research in higher education. We 
choose to discuss higher education because this is a group of society in which it is common to see the confluence of multiple contextual variables, such as gender, age, level of academic accomplishment, year of university entry, and education major.

Gallè et al. (2020) carried out a survey among 2125 undergraduates from three Italian universities. Their results showed a good level of knowledge about Covid-19 and its control, mainly among life sciences students $(n=1047)$. In Indonesia, Fauzi et al. (2020) used Google Forms ${ }^{\mathrm{TM}}$ to prepare a self-administered survey questionnaire to determine the Covid-19 literacy among 290 university biology education students from the largest private university in this country. Their outcomes indicated that very few participants had high levels of Covid-19 literacy. Fauzi et al. (2020) mention that this is something that is worrying, because university biology education students, as future Biology teachers, are expected to promote a critical understanding about Covid-19 in the communities around them. Most importantly, they concluded that "education about COVID-19 for them [university Biology Education students] needs to be improved and various lecture assignments are expected to be linked to COVID-19 knowledge" (p. 8).

In another institutional-based cross-sectional study, Khasawneh et al. (2020) concluded that, from a sample of 1404 medical learners in Jordan who answered an online questionnaire, participants tended to depend more on social media rather than scientific sources when obtaining information about Covid-19. In a study conducted by Hamza et al. (2021), 238 senior pharmacy students at the British University in Egypt answered a 12-item online questionnaire. The results of this survey showed that social media (70\%), articles (48\%), and TV (48\%) were their main source of information about the Covid-19 pandemic. Another interesting result was that even though $72.5 \%$ of the senior pharmacy students demonstrated a good level of knowledge about Covid-19, 50.5\% admitted not wearing masks when leaving their house.

In Jordan, Olaimat et al. (2020) conducted an online cross-sectional study in which 2083 undergraduate or graduate students from different private and state universities answered a self-administered, online questionnaire. Some of the key findings of their study include the following: (1) $56.5 \%$ of the participants displayed good knowledge about Covid-19; (2) respondents' knowledge seemed to be related to their college of study and educational level; (3) medical sciences students showed the highest mean score $(82.8 \%)$; (4) graduates had significantly higher scores than undergraduates; and (5) Internet (e.g., electronic news websites and social media) (77.1\%) and mass media (e.g., $\mathrm{TV}$, newspapers) (67.6\%) were the two most common sources of the participants' information about Covid-19.

On the basis of the literature reviewed above, it is clear that studies focusing on the examination of university students' Covid-19 literacy levels are only now emerging and therefore there is still much work to be done by future academics in this respect. In particular, the lack of literature relating to Covid-19 literacy in higher education in Latin American countries is notorious. With this in mind, our research contributes to addressing this gap in the literature by providing relevant evidence about the Covid-19 literacy level of undergraduates and graduates at a Colombian university. The current population of Colombia is $\sim 48$ million (DANE, 2019). In this Latin American country, the first confirmed case of Covid-19 was reported on March 6 (Johns Hopkins University \& Medicine, 2020) and by the 2 December 2020, the country reported 1,334,089 confirmed cases-45.4\% (606,041) were people between 20 and 39 years old; 1,225,635 (91.8\%) recovered; and 37,117 deaths (National Institute of Health, Colombia, 2020). A nationwide lockdown was announced by the Colombian government on 25 March 2020 and was extended until 31 August 2020. 


\section{Research Design and Method}

\subsection{Sample and Sampling}

As mentioned earlier, our institutional-based cross-sectional study was conducted from 9 to 20 November 2020. Permission to conduct the study was obtained from the university's ethics committee. We used the online sample size calculator Raosoft ${ }^{\circledR}$ (raosoft.com) based on a 50\% response rate, a 99\% confidence interval, and a 5\% margin of error with a total student population of 2,440,367 enrolled in private and state Colombian universities (Ministry of National Education, Colombia, 2018). The minimum number of university students required for the study was 664 . In fact, 4168 university students participated. This value is 6.2 times greater than the minimum value required. This gives an idea of the importance of our sample size. Table 1 presents characteristics of the population who participated in this cross-sectional study. Gender, age, level of academic accomplishment, year of entry, and education major are the demographic variables considered in this study because these are characteristics that can be explored in almost every higher education population (Gallè et al., 2020; Hamza et al., 2021; Olaimat et al., 2020). It is important to clarify that the participating students were chosen by "convenience sampling" (Bryman, 2016, p. 187). Much of the reason for this is that they were available

Table 1 Demographics of the study sample

\begin{tabular}{|c|c|c|}
\hline Characteristic & Response & $n(\%=[n / 4168] \times 100)$ \\
\hline \multirow[t]{3}{*}{ Gender } & Females & $2301(55.2)$ \\
\hline & Males & $1849(44.3)$ \\
\hline & Prefer not to say & $18(0.4)$ \\
\hline \multirow[t]{3}{*}{ Age (years) } & $\leq 20$ & $2059(49.4)$ \\
\hline & $21-25$ & 1332 (31.9) \\
\hline & $\geq 26$ & 777 (18.6) \\
\hline \multirow{2}{*}{$\begin{array}{l}\text { Level of academic accom- } \\
\text { plishment }\end{array}$} & Undergraduate & 3199 (76.7) \\
\hline & Graduate & $969(23.2)$ \\
\hline \multirow[t]{4}{*}{ Year of entry } & 2019-2020 & $2291(54.9)$ \\
\hline & 2017-2018 & $1103(26.4)$ \\
\hline & 2015-2016 & $584(14.0)$ \\
\hline & $<2015$ & $190(4.5)$ \\
\hline \multirow[t]{13}{*}{ Education majors } & Architecture and design & $368(8.8)$ \\
\hline & Arts and humanities & $245(5.9)$ \\
\hline & Business administration & $558(13.4)$ \\
\hline & Economics & $290(6.9)$ \\
\hline & Education & $58(1.4)$ \\
\hline & Engineering & $1217(29.1)$ \\
\hline & $\begin{array}{l}\text { Interdisciplinary Center for Studies on Develop- } \\
\text { ment (ICSD) }\end{array}$ & $58(1.4)$ \\
\hline & Law & $370(8.9)$ \\
\hline & Medicine & $185(4.4)$ \\
\hline & Office of the Dean of Students (ODS) & $19(0.4)$ \\
\hline & School of Government & $109(2.6)$ \\
\hline & Sciences & $369(8.9)$ \\
\hline & Social Sciences & $322(7.7)$ \\
\hline
\end{tabular}


to the research team. Participants reviewed an informed consent paragraph when they started the questionnaire; consent was given by completing the anonymous survey and submitting it via Google Forms ${ }^{\mathrm{TM}}$. Participation was voluntary, respondents were asked to give truthful answers. Given the anonymous character of the survey, no personal identifiers were required.

\subsection{Study Instrument}

We decided to use the pre-validated Covid-19 literacy questionnaire (CLQ) designed by Fauzi et al. (2020) for the following reasons: (1) the CLQ was specifically created and evaluated "to explore students' COVID-19 literacy level" (Fauzi et al., 2020, p. 3); and (2) this instrument was tested with university students (our target population). We obtained access to the original version of the CLQ (Fauzi et al., 2020) after sending a request to the professor, Ahmad Fauzi (Universitas Muhammadiyah Malang, Indonesia). To ensure an appropriate adaptation of this original version, we carried out the study in three phases (Bryman, 2016, p. 260). In the first phase, we received the comments and suggestions of an expert in evolutionary genetics, an expert in epidemiology, and an expert in public health. In the second phase, the experts' comments were complemented with a literature search based on the most recent available information from the Ministry of Health and Social Protection (Colombia), the Center for Disease Control and Prevention (USA), and the World Health Organization (WHO). In the third phase, the instrument was pilot tested with five students from other Colombian universities before it was used by the study participants. To measure the internal consistency reliability of the questions, the Cronbach's alpha coefficient was calculated. The coefficient obtained was 0.744 . According to George and Mallery (2020), this value corresponds to an "acceptable" (p. 244) internal consistency. On average, it took 5 min to complete the questionnaire. The five pilot test participants reported that the questions and response options were easy to understand.

The adapted version of the questionnaire included multiple-choice questions, or yes/no/I don't know options, and consisted of a total of 25 questions divided into five sections. As represented in Fig. 1, scientific media literacy, health literacy, and scientific literacy are the major components of Covid-19 literacy. Accordingly, the questionnaire focused on these elements as follows: part 1 was related to scientific media literacy while parts 2 to 5 were related to both health literacy and scientific literacy. Specifically, part 1 (five questions) dealt with source of information (e.g., Which source do you believe can provide accurate information regarding Covid-19?). Part 2 (five questions) explored participants' knowledge about the spread and transmission of the disease (e.g., Does SARS-CoV-2 spread faster than SARS-CoV-1 and MERS-CoV?). Part 3 included three questions about cause and symptoms (e.g., What causes Covid-19?). Part 4 addressed seven questions about the prevention of transmission (e.g., How do you protect yourself from being infected with SARSCoV-2?). Finally, part 5 had five questions about diagnostic, treatment, and fatality rate (e.g., Can a person recover after contracting Covid-19?).

In our analysis, we did not include the five questions of part 1 of the questionnaire because these dealt with the source of information. Also, participants' responses to the following questions were not considered because of multiple possible correct answers: "How can someone get Covid-19?" (question 8), "What are the symptoms of someone being infected with SARS-CoV-2?" (question 12), and "How do you protect yourself from being infected with SARS-CoV-2?" (question 20). In addition, the following question was not considered in this analysis due to lack of agreement among the scientific community (Petrosillo et al., 2020): "Does SARS-CoV-2 spread faster than severe acute respiratory syndrome coronavirus (SARS-CoV-1) and Middle East respiratory syndrome coronavirus (MERS-CoV)?" 
(question 10). Thus, at this level of our analysis, we only considered students' responses to sixteen out of the twenty-five questions. Each correct response was given a score of 1, and 0 for both wrong and "I don't know" responses. The possible scores were the sum of all correct responses ranging from zero to sixteen. We should acknowledge that given scientific uncertainties surrounding the Covid-19 pandemic, it is possible that an "I don't know" answer exhibits a cautious appropriate attitude. However, this is difficult to judge. Therefore, caution needs to be taken regarding the interpretation of our contextual findings.

\subsection{Data Collection}

Data collection represents a crucial aspect of this institutional-based cross-sectional study. The 25-item questionnaire is the instrument used in this study to collect data about the Covid-19 literacy levels of participants. This is a legitimate data collection method because this questionnaire allows data to be collected to answer our two research questions. We used Google Forms ${ }^{\mathrm{TM}}$ to prepare the self-administered questionnaire. Specifically, on 9 November 2020, the Office of the Dean of Students sent a link to the online version of the questionnaire in Spanish via email to all students in the university. Data collection finished eleven days after this, on 20 November 2020.

\subsection{Data Analysis}

A total of 4221 responses were received, but fifty-three were excluded because these did not meet basic criteria and/or were incomplete. Finally, the responses of 4168 participants were used for further analysis. Analysis was carried out at two levels. The first level dealt with the first research question, "What is Colombian university students' level of Covid-19 literacy?" Here, the completed questionnaire data were extracted from Google Forms ${ }^{\mathrm{TM}}$ and exported to a Microsoft Excel®. Data were analyzed using the Statistical Package for the Social Sciences (SPSS $囚)$. Descriptive analyses, such as arithmetic mean, frequencies, percentages, and standard deviations (SD) were used to summarize our outcomes. At the second level of our analysis, the Covid-19 literacy level of each participant was determined as a response to the second research question, "How is students' Covid-19 literacy level related to demographic variables?" Additionally, associations between independent variables and dependent variables were assessed. To be clear, gender, age, level of academic accomplishment, year of entry, and education major were assumed as independent variables, while the Covid-19 literacy score was taken as a dependent variable. A one-way analysis of variance (ANOVA) test was carried out in order to assess any difference in mean score by each independent variable. We considered as statistically significant a $p$-value of less than 0.05 .

\section{Results}

The results are presented in two sections: The first section addresses the examination of participants' Covid-19 literacy level. The second focuses on the exploration of possible relationships between Covid-19 literacy level and demographic variables (gender, age, level of academic accomplishment, year of entry, and education major). 


\subsection{Results of Participants' Responses to the Questionnaire}

In this section, the results of the five parts of the questionnaire are summarized in five tables (Tables 2, 3, 4, 5, and 6). The first part asked about source of information about Covid-19 (Table 2). The most commonly stated sources of knowledge were the Internet (86.8\%) and social media (64.7\%) (question 1). More than half (58.5\%) of questionnaire respondents believed that health workers are a source that can provide accurate information about this disease (question 2). Government media (57.8\%) and Internet (54\%) were also considered reliable sources by a significant number of participants. Additionally, Table 2 shows that a large percentage of university students knew about Covid-19 before it was declared to have entered Colombia (question 3: 89.3\%) and had heard information/messages related to the protection of common places (question $4: 85.8 \%$ ) and the traveling/ tourism protocols to prevent transmission (question 5: 80.1\%).

Responses of the 4168 study participants regarding Covid-19 spread and transmission are shown in Table 3. The majority of the participating students accepted the possibility that Covid-19 can be spread to the area around them (question 6: 79.1\%). A promising result is that a very large percentage of the respondents seemed to be aware that everyone can become infected (question 7: 97.8\%). Moreover, we found that "droplets of saliva exhaled while talking" was the transmission route of Covid-19 most recognized by participants (question 8: 89.4\%). In contrast with these outcomes, the responses to questions 9 and 10 indicate that a considerable number of students did not have a clear understanding about whether (1) a person who has been cured of Covid-19 is not still able to transmit the disease a few days after being declared cured and (2) SARS-CoV-2 spreads faster than SARS-CoV-1 and MERS-CoV.

As shown in Table 4, a significantly higher number of the respondents knew that Covid19 was caused by a virus (question 11: 97.5\%). With respect to the symptoms of this disease, $97.8 \%$ of the students considered that not all people infected show symptoms (question 13). In relation to this, most stated symptoms of Covid-19 were fever (98.4\%), loss of taste (91.8\%), and loss of smell (90.8\%) (question 12).

The participants' prevention of Covid-19 transmission knowledge is shown in Table 5. The results suggest that it is clear to the majority of the students when people should be isolated (question 14: 97.6\%; question 16: 96.1\%). Nonetheless, it seems that there is a lack of clarity about how long an infected person should be isolated for. To be precise, participants' responses to question 15 indicate that they are divided between the options: "8-14 days" (51.6\%) and "15-21 days" (46\%). Furthermore, a high percentage of the respondents to the questionnaire appeared to know some of the acceptable (question 18: 92.8\%; question 19: 80\%) and unacceptable (question 17: 86.4\%) actions to prevent people getting Covid-19. It is also important to mention that the most recognized ways to protect people from being infected with SARS-CoV-2 (question 20) were the use of a mask (98.9\%), handwashing (98.8\%), and physical distancing $(98.3 \%)$.

Finally, Table 6 shows the outcomes of part 5 of the questionnaire. We found that $61.2 \%$ of the university students knew that the PCR test is currently used as diagnostic for Covid19 (question 21). This is a favorable result. However, a point of concern is that $25.8 \%$ of the respondents considered that to make a culture of oral or nasal fluids in specialized media can be used as a diagnostic test for this disease. In addition, although nearly all the students agree that people can recover after contracting Covid-19 (question 22: 99.2\%), the eventual role of (1) vaccination (question 23) is still unclear to some of the participants as well as the contribution of (2) AIDS drugs (question 24) to deal with this disease. Furthermore, 
Table 2 Response of study participants to source of information questions

\begin{tabular}{|c|c|c|}
\hline Question & Response & $n(\%=[n / 4168] \times 100)$ \\
\hline \multirow{9}{*}{$\begin{array}{l}\text { 1. Where do you get information about } \\
\text { Covid-19?* }\end{array}$} & Family & $2201(52.8)$ \\
\hline & Friends or neighbor & $1008(24.1)$ \\
\hline & Health workers & $1470(35.2)$ \\
\hline & Television & $2134(51.1)$ \\
\hline & Internet & $3621(86.8)$ \\
\hline & Social media & $2699(64.7)$ \\
\hline & Lecturers & $757(18.1)$ \\
\hline & Government media & $1953(46.8)$ \\
\hline & Other & $34(0.8)$ \\
\hline \multirow{9}{*}{$\begin{array}{l}\text { 2. Which source do you believe can provide } \\
\text { accurate information regarding Covid-19?* }\end{array}$} & Family & $352(8.4)$ \\
\hline & Friends or neighbor & $72(1.7)$ \\
\hline & Health workers & $2440(58.5)$ \\
\hline & Television & $966(23.1)$ \\
\hline & Internet & $2251(54.0)$ \\
\hline & Social media & $524(12.5)$ \\
\hline & Lecturers & $852(20.4)$ \\
\hline & Government media & $2411(57.8)$ \\
\hline & Other & $99(2.3)$ \\
\hline \multirow{3}{*}{$\begin{array}{l}\text { 3. Did you know about Covid-19 before it } \\
\text { was declared to have entered Colombia? }\end{array}$} & Yes & $3723(89.3)$ \\
\hline & No & $401(9.6)$ \\
\hline & I don't know & $44(1.0)$ \\
\hline \multirow{3}{*}{$\begin{array}{l}\text { 4. Have you ever heard information/messages } \\
\text { about how to protect the common places to } \\
\text { prevent transmission of Covid-19? }\end{array}$} & Yes & $3578(85.8)$ \\
\hline & No & $458(10.9)$ \\
\hline & I don't know & $132(3.1)$ \\
\hline \multirow{3}{*}{$\begin{array}{l}\text { 5. Have you ever heard information/messages } \\
\text { related to traveling/tourism protocols to } \\
\text { prevent transmission of Covid-19? }\end{array}$} & Yes & $3339(80.1)$ \\
\hline & No & $754(18.0)$ \\
\hline & I don't know & $75(1.7)$ \\
\hline
\end{tabular}

*Students were given the opportunity to choose more than one option.

only $23.8 \%$ of the participating students knew that the fatality rate of Covid-19 was not higher than SARS-CoV-1 and MERS-CoV (question 25).

\subsection{Relationships Between Covid-19 Literacy and Demographic Variables}

Table 7 shows the comparison of demographic characteristics and mean and total scores of participants' responses to sixteen out of the twenty-five questions in parts 2 (spread and transmission; questions 6. 7, and 9 in Table 3); 3 (cause and symptoms; questions 11 and 13 in Table 4); 4 (prevention; questions 14 to 19 in Table 5); and 5 (diagnostic, treatment, and fatality; questions 21 and 25 in Table 5) of the questionnaire. Sixteen was the maximum possible and the desirable total score. The overall mean score was $12.0 \pm 1.78$ with variables such as $21-25$-year age group $(12.36 \pm 1.77)$, graduate students $(12.34 \pm 1.66),<2015$ year of entry group $(12.65 \pm 1.66)$, and medical students $(13.39 \pm 1.46)$ having significantly higher mean scores. 


\section{Discussion}

This institutional-based cross-sectional study aims to determine the Covid-19 literacy levels of Colombian university students. To reiterate (Fig. 1), the major components of Covid-19 literacy are scientific media literacy, health literacy, and scientific literacy. The importance of this research is that it provides baseline information for the development of effective evidence-based strategies necessary to ensure a Covid-19 literate society. With this in mind, we should stress that to the best of our knowledge, this is the first study that has investigated Covid-19 literacy among university students in Colombia. An overview of the outcomes shows that the overall mean score of the participants' Covid-19 literacy level is $12.0 \pm 1.78$ which corresponds to a moderate level (sixteen was the maximum possible and the desirable total score). This reinforces the idea that more attention should be given to the promotion of Covid-19 literacy since it is a key aspect within the construction, implementation, and evaluation of global strategies not only to overcome the Covid-19 crisis but also to learn from it in the post-pandemic era (Alahdal et al. 2020; Erduran, 2020b; Zhu \& Liu, 2020).

As previously mentioned, part 1 of the questionnaire was related to scientific media literacy while parts 2 to 5 were related to both health literacy and scientific literacy. These sections and our two research questions guided the following discussion. Reflecting on the first research question of this study, we explored the Covid-19 literacy level of Colombian university students. Part 1 of the questionnaire dealt with source of information. The results indicate that Internet $(86.8 \%)$ and social media $(64.7 \%)$ are the two most popular sources of information from which participants receive information about Covid-19 (question 1 in Table 2). This is a key outcome because Internet and social media are sources which can exacerbate Covid-19 infodemic and paperdemic, and thus present citizens with false and/or inaccurate information regarding this pandemic (Dinis-Oliveira, 2020; Habersaat et al., 2020; Palayew et al., 2020; Sentell et al., 2020). There is a particular characteristic of social media that can explain its popularity among participating students, namely easy access to engaging audiovisual content. Hence, it makes sense to assert that Covid-19 literacy emerges as a possibility to avoid naïve and uncritical exposure to misinformation relating to the Covid-19 pandemic which can be communicated in social media.

Part 2 of the questionnaire addresses participants' knowledge about Covid-19 spread and transmission. The results suggest that the majority of the respondents had a good knowledge about how someone can become infected with SARS-CoV-2 (question 8 in Table 3). In particular, it is interesting to find that $83.1 \%$ of the students appeared to be aware that aerosols are another major route of transmission (WHO, 2020e). It is therefore reasonable to suppose that these students will not have much trouble in understanding why it is important to move activities outdoors and improve indoor air using ventilation and filtration (Prather et al., 2020).

Another interesting finding is that $39.8 \%$ of the students chose the "I do not know" option when were asked whether an individual who has been cured of Covid-19 was (or not) still able to transmit the disease a few days after being declared cured (question 9 in Table 3). A plausible explanation for this is that these students preferred to convey a cautious attitude. This explanation makes sense whether we acknowledge that at this moment we do not know for sure what the conditions for Covid-19 to be transmitted are. Also, $43.2 \%$ of the students considered that SARS-CoV-2 spreads faster than severe SARSCoV-1 and MERS-CoV (question 10 in Table 3). It is difficult to assess how correct this consideration is, due to the lack of agreement among some academics. On the one hand, 
Petrosillo et al. (2020) mentions that the $R_{0}$ of Covid-19 "(2.0-2.5) is still controversial. It is probably slightly higher than the $R_{0}$ of SARS (1.7-1.9) and higher than that of MERS $(<1)$ " (p. 729). On the other hand, Liu et al. (2020) contend that the $R_{0}$ of Covid-19 is between 2 and 3, while the $R_{0}$ of SARS is estimated to range between 2 and 5. It should be pointed out that the estimation of $R_{0}$ may vary depending on the population under study (Najafimehr et al. 2020).

Part 3 of the questionnaire asked about Covid-19 cause and symptoms. An interesting point to discuss here is that although "diarrhea" is a symptom that someone infected with SARS-CoV-2 may present (Ciotti et al. 2020) AND "fever" was the symptom that the university students most associated with Covid-19 (question 12: 98.4\%) while "diarrhea" was recognized as a symptom by only $52.8 \%$ of the participants. A plausible explanation for this is that symptoms of Covid-19 are commonly associated with those of the common cold, such as a sore throat and fever. Another key finding related to the symptoms of Covid-19 is that $97.8 \%$ of the respondents appeared to be aware that not all people infected with SARS-CoV-2 show symptoms (question 13 in Table 4). This might be explained by the fact that the case of asymptomatic infected people is a central aspect of almost every awareness campaign of Covid-19 that university students easily find in the media. Thus, we can agree that students' awareness of this is a step in the right direction to overcome the Covid-19 pandemic since the fact that people who are infected can be asymptomatic leads to greater difficulty in controlling transmission (Li et al., 2020a, 2020b, 2020c).

Part 4 of the questionnaire focused on the prevention of Covid-19 transmission. According to $\mathrm{Li}$ et al., 2020a, 2020b, 2020c, p. 6558), "isolation is the most effective way" to prevent the spread of SARS-CoV-2. A high percentage of the university students seemed to know that isolation (questions 14 and 16 in Table 5) and avoiding physical contact with infected people (questions 18 and 19 in Table 5) are some actions which have been proved to prevent transmission (Centers for Disease Control \& Prevention, 2020; Ciotti et al. 2020). Based on these results, it could be speculated that students were aware of the importance of isolation and avoiding physical contact as relevant action for the prevention of Covid-19 transmission because they have experienced these by themselves through nationwide lockdowns decreed by the Colombian government as well as through physical distancing protocols adopted by retail stores and shopping malls in this country. These findings add valuable support to the use of a mask (98.9\%), handwashing (98.8\%), and physical distancing (98.3\%) as self-protection measures adopted by almost all the participants (question 20 in Table 5). However, this does not necessarily mean that they are convinced that these are effective measures. Much of the reason for this is that the adoption of self-protection measures is a complicated issue that is influenced by many personal variables which are not explored in this study.

Another point worth discussing here is that despite a general consensus among the health authorities (Centers for Disease Control \& Prevention, 2020; WHO 2020e), only $51.6 \%$ of the students knew that the recommended time of quarantine is 14 days (question 15 in Table 5). We cannot drastically say that $46 \%$ of the students who chose the option "15-21 days" are wrong. In this sense, it is constructive and reasonable to speculate that even if the isolation period recommended by the health authorities is 14 days, the respondent who knows the recommendation may still think that a more cautious attitude is appropriate. This speculation is supported by the fact that question 15 cannot distinguish between those who do not know this recommendation from those who are just cautious.

Furthermore, it is noteworthy that we found an interesting cultural aspect related to the prevention of Covid-19 transmission. A high percentage (86.4\%) of participants knew that the utilization of hot and salty water for bathing is not a way for a person to avoid catching 


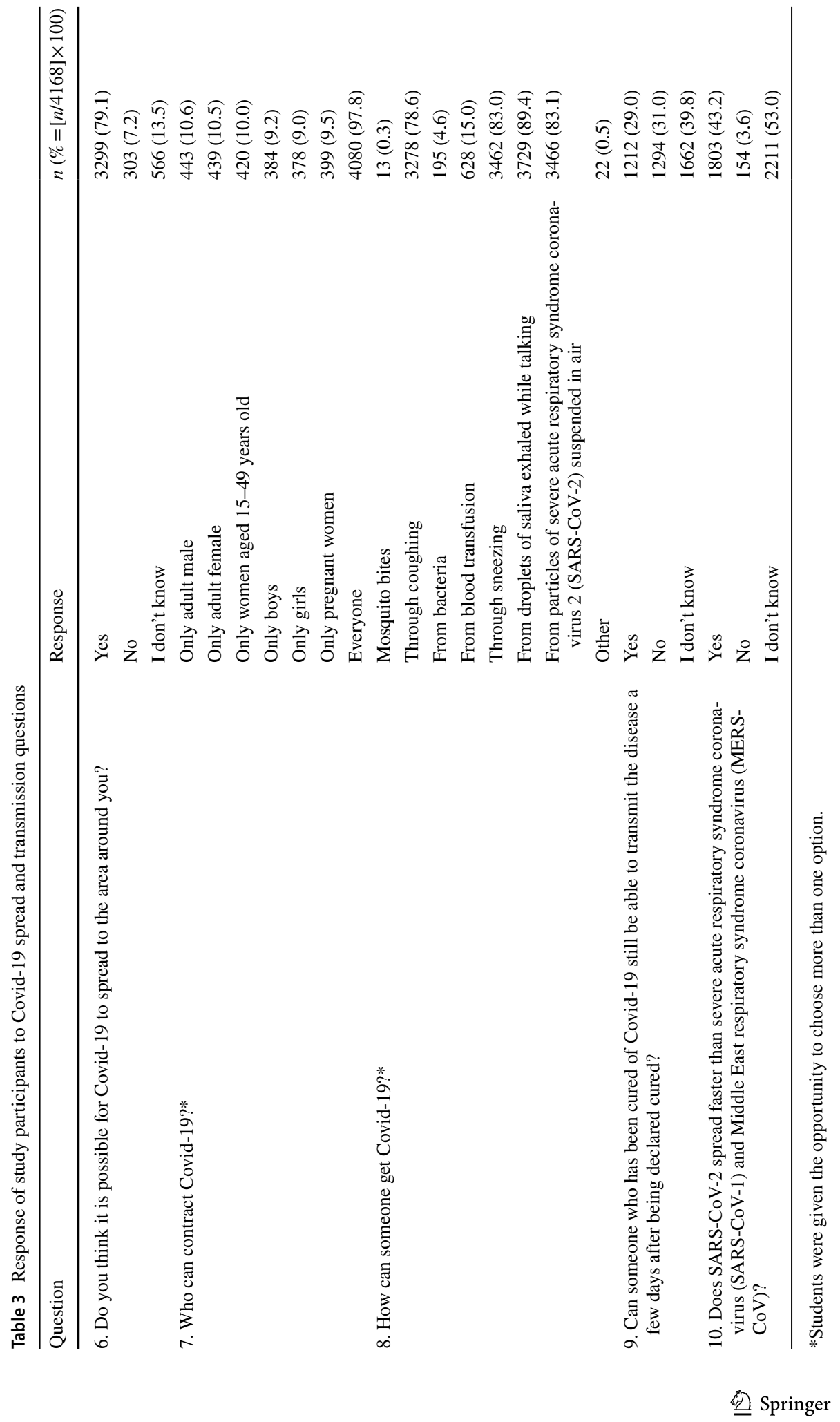


Table 4 Response of study participants to Covid-19 cause and symptoms questions

\begin{tabular}{|c|c|c|}
\hline Question & Response & $n(\%=[n / 4168] \times 100)$ \\
\hline \multirow[t]{6}{*}{ 11. What causes Covid-19? } & Mosquito & - \\
\hline & Sexual intercourse & $1(0.02)$ \\
\hline & Virus & $4066(97.5)$ \\
\hline & Bacteria & $50(1.1)$ \\
\hline & Vaccination & $1(0.02)$ \\
\hline & Other & $50(1.1)$ \\
\hline \multirow{13}{*}{$\begin{array}{l}\text { 12. What are the symptoms of someone infected with } \\
\text { SARS-CoV-2?* }\end{array}$} & Fever & $4102(98.4)$ \\
\hline & Headache & $3632(87.1)$ \\
\hline & Skin rashes & $532(12.7)$ \\
\hline & Joint pain & $1947(46.7)$ \\
\hline & Red eye & $443(10.6)$ \\
\hline & Fatigue & $3370(80.8)$ \\
\hline & Sore throat & $3434(82.3)$ \\
\hline & Loss of smell & $3788(90.8)$ \\
\hline & Loss of taste & $3830(91.8)$ \\
\hline & Diarrhea & $2204(52.8)$ \\
\hline & Conjunctivitis & $495(11.8)$ \\
\hline & Nasal congestion & $2355(56.5)$ \\
\hline & Other & $41(0.9)$ \\
\hline \multirow{3}{*}{$\begin{array}{l}\text { 13. Do all people infected with SARS-CoV-2 show the } \\
\text { symptoms presented in the previous questions? }\end{array}$} & Yes & $43(1.0)$ \\
\hline & No & $4080(97.8)$ \\
\hline & I don't know & $45(1.0)$ \\
\hline
\end{tabular}

*Students were given the opportunity to choose more than one option.

Covid-19 (question 17 in Table 5). A plausible reason for this is that the academic atmosphere in which university students are commonly involved helps them to demystify the hot and salty water myth to avoid or cure several diseases. This is a myth (practice) that existed in the Colombian culture even before the Covid-19 pandemic. Although Archila et al. (2020b) invite us to be respectful of the culture(s) of this Latin American country, we should note that Sahoo et al. (2020) highlight the importance of promoting Covid-19 literacy to demystify the hot and salty water myth, among many others.

Finally, part 5 of the questionnaire dealt with students' knowledge about Covid-19 diagnosis, treatment, and fatality rates. Although it is well established that the PCR test is currently used as a diagnostic for Covid-19 (Miller et al. 2020; Weissleder et al. 2020), only $61.2 \%$ of the respondents knew this (question 21 in Table 6). One reason for this might be that answering question 21 requires a basic knowledge of the PCR test that not all the students seem to have developed. This speculation makes sense whether we take into consideration the fact that the participants in this study are students from different majors (not only medicine or science). Another key outcome was that less than half (44.1\%) of the university students knew about the role of an eventual vaccine (question 23 in Table 6). It is hard to imagine that vaccination could become accepted among university students in Colombia when many of them do not have a clear idea of what its role is in the midst of the Covid-19 pandemic. As several scholars note, this form of illiteracy about Covid-19 can be harnessed by the anti-vaccine movement (Ball \& Maxmen, 2020; Kearns \& Kearns, 2020; Saribas \& Çetinkaya, 2020). 
Table 5 Response of study participants to prevention of Covid-19 transmission questions

\begin{tabular}{|c|c|c|}
\hline Question & Response & $n(\%=[n / 4168] \times 100)$ \\
\hline \multirow{3}{*}{$\begin{array}{l}\text { 14. Does someone who is suspected of having } \\
\text { contracted Covid- } 19 \text { or who has symptoms } \\
\text { similar to people with Covid- } 19 \text { have to be } \\
\text { isolated from others? }\end{array}$} & Yes & $4069(97.6 \%)$ \\
\hline & No & $52(1.2)$ \\
\hline & I don't know & $47(1.1)$ \\
\hline \multirow{5}{*}{$\begin{array}{l}\text { 15. How long should an infected person be } \\
\text { isolated? }\end{array}$} & 1-7 days & $20(0.4)$ \\
\hline & $8-14$ days & $2151(51.6)$ \\
\hline & 15-21 days & $1920(46.0)$ \\
\hline & 22-28 days & $38(0.9)$ \\
\hline & I don't know & $39(0.9)$ \\
\hline \multirow{3}{*}{$\begin{array}{l}\text { 16. If there are people who have just had direct } \\
\text { physical contact with people with Covid-19, do } \\
\text { they have to isolate as well? }\end{array}$} & Yes & $4007(96.1)$ \\
\hline & No & $51(1.2)$ \\
\hline & I don't know & $110(2.6)$ \\
\hline \multirow{3}{*}{$\begin{array}{l}\text { 17. Can a person avoid getting Covid-19 by bath- } \\
\text { ing with hot or salty water? }\end{array}$} & Yes & $41(0.9)$ \\
\hline & No & $3604(86.4)$ \\
\hline & I don't know & $523(12.5)$ \\
\hline \multirow{3}{*}{$\begin{array}{l}\text { 18. Can a person avoid getting Covid-19 if s/he } \\
\text { avoids physical contact with someone who has } \\
\text { contracted this disease? }\end{array}$} & Yes & $3869(92.8)$ \\
\hline & No & $221(5.3)$ \\
\hline & I don't know & $78(1.8)$ \\
\hline \multirow{3}{*}{$\begin{array}{l}\text { 19. Can a person avoid getting Covid- } 19 \text { by } \\
\text { avoiding contact with blood or other bodily } \\
\text { fluids (urine, saliva, etc.)? }\end{array}$} & Yes & $3338(80.0)$ \\
\hline & No & $348(8.3)$ \\
\hline & I don't know & $482(11.5)$ \\
\hline \multirow[t]{8}{*}{$\begin{array}{l}\text { 20. How do you protect yourself from being } \\
\text { infected with SARS-CoV-2?* }\end{array}$} & $\begin{array}{l}\text { Using a mosquito repellent } \\
\text { cream or sprayer }\end{array}$ & $4(0.09)$ \\
\hline & Using protective clothing & $348(8.3)$ \\
\hline & $\begin{array}{l}\text { Using a condom during sexual } \\
\text { intercourse }\end{array}$ & $46(1.1)$ \\
\hline & Not having sexual relations & $177(4.2)$ \\
\hline & Using a mask & $4123(98.9)$ \\
\hline & Washing my hands & $4122(98.8)$ \\
\hline & Physical distancing & 4099 (98.3) \\
\hline & Other & $22(0.5)$ \\
\hline
\end{tabular}

*Students were given the opportunity to choose more than one option.

Fatality rates of SARS-CoV-2 compared with SARS-CoV-1 and MERS-CoV is another aspect that deserves more attention in the promotion of Covid-19 literacy. Chen (2020) reports that SARS-CoV-2 can be fatal in $\sim 3 \%$ of cases while SARS-CoV-1 in $\sim 10 \%$ and MERS-CoV in $\sim 40 \%$. A low percentage $(23.8 \%)$ of the participating students seemed to know this (question 25 in Table 6). A plausible explanation may be linked to the fact that both the SARS-CoV-1 and MERS-CoV epidemics were not much reported in Colombia. Therefore, the knowledge about these viruses is limited among university students in this country.

Reflecting on the second research question of this study, we explored the relationships between the students' Covid-19 literacy level and demographic variables, namely, gender, age, level of academic accomplishment, year of entry, and education major. Our findings suggest that the students' age influenced their understanding of Covid-19 (Table 7). Specifically, students between the ages of 21 and 25 demonstrate higher literacy levels than 
the $\leq 20$-year age group. We consider that this piece of evidence can be used for the Murillo-Llorente and Perez-Bermejo's (2020) claim that promoting Covid-19 literacy among teenagers should be a priority. Also, we found that undergraduates showed lower mean scores than graduates (Table 7). This outcome adds evidence to the recommendation that undergraduate students should be recognized as a population which needs more Covid19 literacy support in comparison with their counterpart (Olaimat et al. 2020). Year of entry to the university was another demographic variable that seemed to influence the participants' Covid-19 literacy levels. To be clear, $<2015$ group had higher mean scores than 2015-2016, 2017-2018, and 2019-2020 groups (Table 7). This result is consistent with that related to students' age because the $<2015$ group was unlikely to have teenagers in it. To close this section, it is important to mention that medical students revealed the highest mean score $(13.39 \pm 1.46)$. Here, there are two plausible explanations. It is likely that the medical students showed a better score because of their upcoming careers as physicians. A second explanation might be that they are already frontline workers as assistants in Colombian health facilities during this pandemic, and this is probably what enabled them to develop higher Covid-19 literacy levels.

\section{Conclusions}

In the first research question of this study, we explored the Covid-19 literacy level of Colombian university students. From the evidence provided in this article, we can conclude that the participants' level is moderate. Arguably, passing from moderate to a high level would require giving more attention to some aspects of Covid-19 literacy, such as views of information sources, knowledge about Covid-19 spread, prevention, transmission, diagnosis, treatment, and fatality rate. Of course, Covid-19 literacy is not a solution to all the problems related to this pandemic. It is just one element among many others of a global strategy that will allow us not only to overcome this crisis but also to learn from it.

Our second research question asks about possible relationships between the students' Covid-19 literacy level and demographic variables. Our results lead us to conclude that the 21-25-year age group, graduate students, $<2015$ year of entry group, and medical students have significantly higher levels of Covid-19 literacy, while lower levels were identified in the $\leq 20$-year age group, undergraduates, 2019-2020 year of entry group, and arts and humanities students. It is important to clarify that we did not find statistically significant evidence to assert that gender is a variable that influences Covid-19 literacy.

\section{Limitations and Areas for Future Research}

The study's findings reported in this article need to be contextualized in view of its limitations. First of all, we adopted a cross-sectional design (Bryman, 2016); our data were collected over a short period of time (twelve days). Thus, we merely provide a "snapshot" of the Covid-19 literacy level among 4168 students from a Colombian university, although this weakness applies to nearly every cross-sectional study interested in determining some aspects of students' Covid-19 literacy (e.g., Fauzi et al. $2020(N=290)$; Gallè et al. $2020(N=2125)$; Hamza et al. $2021(N=238)$; Olaimat et al. $2020(N=2083))$. Arguably, it would be important to examine how students' Covid-19 literacy levels change (or not) 
over time. This is particularly relevant if we recognize that there are still many unanswered questions about Covid-19 and more information about its main features and effects that will take decades to be studied. Second, the Covid-19 literacy level of the instructors was not explored. This is a considerable weakness of this study if we acknowledge that instructors play a key role in the promotion of Covid-19 literacy. It would be relevant to determine how far Covid-19 literacy levels among students and instructors are (or are not) related. A third major issue is that the sample represents only a single university in Colombia. Given that Covid-19 literacy levels seem to vary across contexts, the generalizability of our empirical research is limited and probably does not extend beyond similar universities with similar demographic characteristics. This is the reason why it is imperative to continue the exploration of Covid-19 literacy in other education levels (not only higher education) and countries around the world.

Despite these limitations, we hope that the outcomes of this cross-sectional study will be used to formulate policies and concrete actions aimed at fostering Covid-19 literacy. On March 11, 2020, Covid-19 was declared a pandemic (WHO 2020b), and deep analyses of its impact on our lives are just beginning. If citizens are illiterate with respect to Covid-19, this facilitates the public misunderstanding of this disease as more and more people are likely to be exposed to misleading information (e.g., infodemic, paperdemic) with disastrous repercussions for democracy. In the case of tertiary education, our findings indicate that variables such as age, level of academic accomplishment, year of entry, and education major should be carefully considered when planning educational interventions for an effective promotion of Covid-19 literacy. Therefore, a future research line could be to explore pragmatic and effective student-centered learning environments relating to the explicit

Table 6 Response of study participants to Covid-19 diagnostic, treatment, and fatality rate questions

\begin{tabular}{|c|c|c|}
\hline Question & Response & $n(\%=[n / 4168] \times 100)$ \\
\hline \multirow{5}{*}{$\begin{array}{l}\text { 21. Which test is currently used as diagnostic } \\
\text { for Covid-19? }\end{array}$} & Blood test & $287(6.8)$ \\
\hline & $\begin{array}{l}\text { Polymerase chain reaction }(\mathrm{PCR}) \\
\text { test }\end{array}$ & $2553(61.2)$ \\
\hline & $\begin{array}{l}\text { Measuring body temperature } \\
\text { with an infrared digital ther- } \\
\text { mometer }\end{array}$ & $62(1.4)$ \\
\hline & $\begin{array}{l}\text { Making a culture of oral or nasal } \\
\text { fluids in specialized media }\end{array}$ & $1079(25.8)$ \\
\hline & I don't know & $187(4.4)$ \\
\hline \multirow{3}{*}{$\begin{array}{l}\text { 22. Can a person recover after contracting } \\
\text { Covid- } 19 \text { ? }\end{array}$} & Yes & 4135 (99.2) \\
\hline & No & $6(0.1)$ \\
\hline & I don't know & $27(0.6)$ \\
\hline \multirow{3}{*}{$\begin{array}{l}\text { 23. At present, scientists are developing a } \\
\text { vaccine for Covid-19. Can people who are } \\
\text { infected with SARS-CoV-2 recover by using } \\
\text { the vaccine? }\end{array}$} & Yes & $758(18.1)$ \\
\hline & No & $1839(44.1)$ \\
\hline & I don't know & $1571(37.6)$ \\
\hline \multirow{3}{*}{$\begin{array}{l}\text { 24. Some countries have reported positive } \\
\text { results when they use AIDS drugs to treat } \\
\text { Covid-19 patients. Will taking a drug prevent } \\
\text { someone from contracting Covid- } 19 \text { ? }\end{array}$} & Yes & $104(2.4)$ \\
\hline & No & $2899(69.5)$ \\
\hline & I don't know & 1165 (27.9) \\
\hline \multirow{3}{*}{$\begin{array}{l}\text { 25. Do Covid-19 patients have a higher fatality } \\
\text { rate than SARS-CoV-1 and MERS-CoV? }\end{array}$} & Yes & $721(17.2)$ \\
\hline & No & $995(23.8)$ \\
\hline & I don't know & $2452(58.8)$ \\
\hline
\end{tabular}


Table 7 Comparison of demographic characteristics and mean and total scores $(N=4168)$

\begin{tabular}{|c|c|c|c|c|c|c|}
\hline \multirow[t]{2}{*}{ Variable } & \multirow[t]{2}{*}{$n$} & \multirow{2}{*}{$\begin{array}{l}\text { Spread and } \\
\text { transmis- } \\
\text { sion } \\
\text { Mean (SD) }\end{array}$} & \multirow{2}{*}{$\begin{array}{l}\text { Cause and symp- } \\
\text { toms } \\
\text { Mean (SD) }\end{array}$} & \multirow{2}{*}{$\begin{array}{l}\text { Prevention } \\
\text { Mean (SD) }\end{array}$} & \multirow{2}{*}{$\begin{array}{l}\text { Diagnostic, } \\
\text { treatment, and } \\
\text { fatality } \\
\text { Mean (SD) }\end{array}$} & \multirow{2}{*}{$\begin{array}{l}\text { Total } \\
\text { Mean (SD) }\end{array}$} \\
\hline & & & & & & \\
\hline \multicolumn{7}{|l|}{ Gender } \\
\hline Females & 2301 & $2.07(0.65)$ & $1.96(0.19)$ & $5.05(0.81)$ & $2.93(1.09)$ & $12.01(1.76)$ \\
\hline Males & 1849 & $2.09(0.63)$ & $1.95(0.23)$ & $5.05(0.87)$ & $3.04(1.12)$ & $12.12(1.81)$ \\
\hline $\begin{array}{l}\text { Prefer not to } \\
\text { say }\end{array}$ & 18 & $2.11(0.58)$ & $2.00(0.00)$ & $5.11(0.67)$ & $3.00(1.08)$ & $12.22(1.21)$ \\
\hline$p$-value & & 0.68 & 0.09 & 0.95 & $0.008^{*}$ & 0.12 \\
\hline \multicolumn{7}{|l|}{ Age groups } \\
\hline$\leq 20$ yrs & 2059 & $2.01(0.66)$ & $1.95(0.21)$ & $4.98(0.87)$ & 2.83 (1.09) & $11.77(1.78)$ \\
\hline $21-25$ yrs & 1332 & $2.14(0.62)$ & $1.96(0.18)$ & $5.08(0.83)$ & $3.18(1.11)$ & $12.36(1.77)$ \\
\hline$\geq 26$ yrs & 777 & $2.17(0.62)$ & $1.94(0.23)$ & $5.16(0.76)$ & $3.05(1.08)$ & $12.32(1.66)$ \\
\hline$p$-value & & $0.000 *$ & 0.06 & $0.000 *$ & $0.000 *$ & $0.000^{*}$ \\
\hline \multicolumn{7}{|c|}{ Level of academic accomplishment } \\
\hline Undergraduate & 3199 & $2.05(0.65)$ & $1.96(0.20)$ & $5.01(0.85)$ & $2.95(1.11)$ & $11.98(1.81)$ \\
\hline Graduate & 969 & $2.17(0.62)$ & $1.95(0.23)$ & $5.16(0.79)$ & $3.07(1.07)$ & $12.34(1.66)$ \\
\hline$p$-value & & $0.000 *$ & 0.15 & $0.000^{*}$ & $0.004 *$ & $0.000^{*}$ \\
\hline \multicolumn{7}{|l|}{ Year of entry } \\
\hline 2019-2020 & 2291 & $2.05(0.66)$ & $1.94(0.23)$ & $5.04(0.85)$ & $2.83(1.07)$ & $11.86(1.77)$ \\
\hline 2017-2018 & 1103 & $2.09(0.62)$ & $1.97(0.18)$ & $5.05(0.82)$ & $3.07(1.13)$ & $12.17(1.77)$ \\
\hline $2015-2016$ & 584 & $2.17(0.61)$ & $1.98(0.14)$ & $5.07(0.83)$ & $3.25(1.11)$ & $12.47(1.74)$ \\
\hline$<2015$ & 190 & $2.18(0.59)$ & $1.95(0.22)$ & $5.08(0.80)$ & $3.44(1.10)$ & $12.65(1.66)$ \\
\hline$p$-value & & $0.000^{*}$ & $0.001 *$ & 0.72 & $0.000 *$ & $0.000^{*}$ \\
\hline \multicolumn{7}{|l|}{ Education majors } \\
\hline $\begin{array}{r}\text { Architecture } \\
\text { and design }\end{array}$ & 368 & $1.98(0.65)$ & $1.94(0.23)$ & $4.98(0.84)$ & $2.57(1.01)$ & $11.47(1.73)$ \\
\hline $\begin{array}{l}\text { Arts and } \\
\text { humanities }\end{array}$ & 245 & $1.89(0.65)$ & $1.93(0.27)$ & $4.93(0.87)$ & $2.54(1.09)$ & $11.29(1.80)$ \\
\hline $\begin{array}{l}\text { Business } \\
\text { administra- } \\
\text { tion }\end{array}$ & 558 & $2.13(0.61)$ & $1.94(0.24)$ & $5.15(0.79)$ & $2.89(1.06)$ & $12.12(1.67)$ \\
\hline Economics & 290 & $2.16(0.65)$ & $1.98(0.15)$ & $5.12(0.82)$ & $3.20(1.04)$ & $12.46(1.57)$ \\
\hline Education & 58 & $2.00(0.67)$ & $1.95(0.22)$ & $4.93(1.13)$ & $2.84(1.18)$ & $11.72(1.92)$ \\
\hline Engineering & 1217 & $2.07(0.62)$ & $1.95(0.21)$ & $4.99(0.87)$ & $2.97(1.10)$ & $11.98(1.77)$ \\
\hline ICSD & 58 & $2.28(0.55)$ & $1.98(0.13)$ & $5.21(0.74)$ & $2.93(0.97)$ & $12.40(1.37)$ \\
\hline Law & 370 & $2.12(0.68)$ & $1.96(0.19)$ & $5.09(0.80)$ & $2.91(1.06)$ & $12.08(1.85)$ \\
\hline Medicine & 185 & $2.27(0.61)$ & $1.98(0.12)$ & $5.26(0.71)$ & $3.88(0.94)$ & $13.39(1.46)$ \\
\hline ODS & 19 & $2.16(0.83)$ & $1.95(0.22)$ & $5.26(0.65)$ & $3.00(0.88)$ & $12.37(1.60)$ \\
\hline $\begin{array}{l}\text { School of gov- } \\
\text { ernment }\end{array}$ & 109 & $2.12(0.62)$ & $1.94(0.24)$ & $5.12(0.76)$ & $2.84(1.13)$ & $12.02(1.89)$ \\
\hline Sciences & 369 & $2.13(0.68)$ & $1.98(0.14)$ & $5.03(0.87)$ & $3.38(1.08)$ & $12.52(1.77)$ \\
\hline Social sciences & 322 & $1.96(0.62)$ & $1.95(0.21)$ & $5.00(0.83)$ & $2.96(1.09)$ & $11.88(1.69)$ \\
\hline$p$-value & & $0.000^{*}$ & 0.06 & $0.000 *$ & $0.000^{*}$ & $0.000^{*}$ \\
\hline
\end{tabular}

$* p<0.05$ statistically significant 
promotion of Covid-19 literacy. In addition, it would be a great contribution to study how Covid-19 literacy levels influence the decisions individuals make.

Acknowledgments The authors are indebted to Andrea Ramirez Varela, Andrew J. Crawford, and Jovana Alexandra Ocampo Cañas for the comments and suggestions that led to improvements in the twenty-fiveitem questionnaire used in this study. Thanks also to Juanita Buriticá, Luisa Restrepo, Manuel Palau, Ricardo Mejía, and Santiago Latorre for their help in piloting the instrument. Special thanks to the Office of the Dean of Students, Universidad de los Andes, Bogotá, Colombia, for its cooperation in this project. Finally, the authors thank the university students for their participation in this study. This institutional-based cross-sectional study was funded by the Vice-Presidency of Research and Creation, Universidad de los Andes, Bogotá, Colombia.

\section{Declarations}

Conflict of Interest The authors have no conflicts of interest to disclose.

\section{References}

Abdel-Latif, M. M. M. (2020). The enigma of health literacy and COVID-19 pandemic. Public Health, 185, 95-96.

Abdel Wahed, W. Y., Hefzy, E. M., Ahmed, M. I., \& Hamed, N. S. (2020). Assessment of knowledge, attitudes, and perception of health care workers regarding COVID-19, a cross-sectional study from Egypt. Journal of Community Health, 45(6), 1242-1251.

Abdelhafiz, A. S., Mohammed, Z., Ibrahim, M. E., Ziady, H. H., Alorabi, M., Ayyad, M., \& Sultan, E. A. (2020). Knowledge, perceptions, and attitude of Egyptians towards the novel coronavirus disease (COVID-19). Journal of Community Health, 45(5), 881-890.

Alahdal, H., Basingab, F., \& Alotaibi, R. (2020). An analytical study on the awareness, attitude and practice during the COVID-19 pandemic in Riyadh, Saudi Arabia. Journal of Infection and Public Health, 13(10), 1446-1452.

Anju, K. J., \& Arulsamy, S. (2020). The knowledge towards coronavirus among the people of Kerala and Tamilnadu. JAC: A Journal of Composition Theory, 13(5), 241-248.

Archila, P. A., Molina, J., \& Truscott de Mejía, A.-M. (2019). Promoting undergraduates' awareness of the importance of thinking critically about false or inaccurate scientific information presented in news articles. Revista Eureka sobreEnseñanza y Divulgación de lasCiencias, 16(13), 1-27.

Archila, P. A., Molina, J., \& Truscott de Mejía, A.-M. (2020a). Using historical scientific controversies to promote undergraduates' argumentation. Science \& Education, 29(3), 647-671.

Archila, P. A., Molina, J., \& Truscott de Mejía, A.-M. (2020b). Using a controversy about health, biology, and indigenous knowledge to promote undergraduates' awareness of the importance of respecting the traditions and beliefs of indigenous communities: The case of paragonimiasis in Colombia. Cultural Studies of Science Education. https://doi.org/10.1007/s11422-020-09978-4.

Archila, P. A., Molina, J., Danies, G., Truscott de Mejía, A.-M., \& Restrepo, S. (2020). Providing undergraduates with opportunities to explicitly reflect on how news articles promote the public (mis)understanding of science. Science \& Education. https://doi.org/10.1007/s11191-020-00175-x.

Ball, P., \& Maxmen, A. (2020). The epic battle against coronavirus misinformation and conspiracy theories. Nature, 581(7809), 371-374.

Bryman, A. (2016). Social research methods. (5th ed.). Oxford University Press.

Centers for Disease Control and Prevention (2020). COVID-19 overview and infection prevention and control priorities in non-us healthcare settings. https://www.cdc.gov/coronavirus/2019-ncov/hcp/non-ussettings/overview/index.html. Accessed 6 November 2020.

Chen, J. (2020). Pathogenicity and transmissibility of 2019-nCoV-A quick overview and comparison with other emerging viruses. Microbes and Infection, 22(2), 69-71.

Ciotti, M., Ciccozzi, M., Terrinoni, A., Jiang, W.-C., Wang, C.-B., \& Bernardini, S. (2020). The COVID-19 pandemic. Critical reviews in clinical laboratory sciences, 57(6), 365-388. 
Clements, J. M. (2020). Knowledge and behaviors toward COVID-19 among US residents during the early days of the pandemic: Cross-sectional online questionnaire. JMIR Public Health and Surveillance, 6(2), 1-11.

Delamater, P. L., Street, E. J., Leslie, T. F., Yang, Y., \& Jacobsen, K. H. (2019). Complexity of the basic reproduction number $\left(\mathrm{R}_{0}\right)$. Emerging Infectious Diseases, 25(1), 1-4.

Departamento Administrativo Nacional de Estadística. (DANE). (2019). Resultados del censo nacional de población y vivienda 2018. https://www.dane.gov.co/index.php/estadisticas-por-tema/demografiay-poblacion/censo-nacional-de-poblacion-y-vivenda-2018/cuantos-somos. Accessed 1 August 2020.

Dinis-Oliveira, R. J. (2020). COVID-19 research: Pandemic versus "paperdemic", integrity, values and risks of the "speed science." Forensic Sciences Research, 5(2), 174-187.

Erduran, S. (2020a). Science education in the era of a pandemic. Science \& Education, 29(2), $233-235$.

Erduran, S. (2020b). Bringing nuance to "the science" in public policy and science understanding. Science \& Education, 29(3), 487-489.

Fauzi, A., Husamah, H., Miharja, F. J., Fatmawati, D., Permana, T. I., \& Hudha, A. M. (2020). Exploring COVID-19 literacy level among biology teacher candidates. Eurasia Journal of Mathematics, Science and Technology Education, 16(7), 1-12.

Gallè, F., Sabella, E. A., Da Molin, G., et al. (2020). Understanding knowledge and behaviors related to CoViD-19 epidemic in Italian undergraduate students: The EPICO study. International Journal of Environmental Research and Public Health, 17(10), 1-11.

George, D., \& Mallery, P. (2020). IBM SPSS statistics 26 step by step. (16th ed.). Routledge.

Habersaat, K. B., Betsch, C., Danchin, M., et al. (2020). Ten considerations for effectively managing the COVID-19 transition. Nature Human Behaviour, 4(7), 677-687.

Hamza, M. S., Badary, O. A., \& Elmazar, M. M. (2021). Cross-sectional study on awareness and knowledge of COVID-19 among senior pharmacy students. Journal of Community Health, 46(1), 139-146.

Hayat, K., Rosenthal, M., Xu, S., Arshed, M., Li, P., Zhai, P., Desalegn, G. K., \& Fang, Y. (2020). View of Pakistani residents toward coronavirus disease (COVID-19) during a rapid outbreak: A rapid online survey. International Journal of Environmental Research and Public Health, 17(10), 1-10.

Honarvar, B., Lankarani, K. B., Kharmandar, A., et al. (2020). Knowledge, attitudes, risk perceptions, and practices of adults toward COVID-19: A population and field-based study from Iran. International Journal of Public Health, 65(6), 731-739.

Johns Hopkins University \& Medicine (2020). Coronavirus resource center. https://coronavirus.jhu.edu/ map.html. Accessed 21 November 2020.

Kearns, C., \& Kearns, N. (2020). The role of comics in public health communication during the COVID19 pandemic. Journal of Visual Communication in Medicine, 43(3), 139-149.

Khasawneh, A. I., Humeidan, A. A., Alsulaiman, J. W., Bloukh, S., Ramadan, M., Al-Shatanawi, T. N., Awad, H. H., Hijazi, W. Y., Al-Kammash, K. R., Obeidat, N., Saleh, T., \& Kheirallah, K. A. (2020). Medical students and COVID-19: Knowledge, attitudes, and precautionary measures. A descriptive study from Jordan. Frontiers in Public Health, 8, 1-9.

Kotian, R. P., Faujdar, D., Kotian, S. P., \& D'souza, B. (2020). Knowledge and understanding among medical imaging professionals in India during the rapid rise of the covid-19 pandemic. Health and Technology, 10(6), 1415-1420.

Lauer, S. A., Grantz, K. H., Bi, Q., et al. (2020). The incubation period of coronavirus disease 2019 (COVID-19) from publicly reported confirmed cases: Estimation and application. Annals of Internal Medicine, 172(9), 577-582.

Li, H., Liu, Z., \& Ge, J. (2020a). Scientific research progress of COVID-19/SARS-CoV-2 in the first five months. Journal of Cellular and Molecular Medicine, 24(12), 6558-6570.

Li, Q., Guan, X., Wu, P., et al. (2020b). Early transmission dynamics in Wuhan, China, of novel coronavirus-infected pneumonia. The New England Journal of Medicine, 382(13), 1199-1207.

Li, S., Feng, B., Liao, W., \& Pan, W. (2020c). Internet use, risk awareness, and demographic characteristics associated with engagement in preventive behaviors and testing: Cross-sectional survey on COVID-19 in the United States. Journal of Medical Internet Research, 22(6), 1-12.

Liu, Q., Xu, K., Wang, X., \& Wang, W. (2020). From SARS to COVID-19: What lessons have we learned? Journal of Infection and Public Health, 13(11), 1611-1618.

Miller, T. E., Garcia Beltran, W. F., Bard, A. Z., et al. (2020). Clinical sensitivity and interpretation of PCR and serological COVID-19 diagnostics for patients presenting to the hospital. The FASEB Journal, 34(10), 13877-13884.

Ministry of National Education, Colombia (2018). Información poblacional. Estadísticas históricas de la educación superior en Colombia. https://hecaa.mineducacion.gov.co/consultaspublicas/content/ poblacional/index.jsf. Accessed 10 July 2020. 
Mousa, K. N. A. A., Saad, M. M. Y., \& Abdelghafor, M. T. B. (2020). Knowledge, attitudes, and practices surrounding COVID-19 among Sudan citizens during the pandemic: An online cross-sectional study. Sudan Journal of Medical Sciences, 15, 32-45.

Murillo-Llorente, M. T., \& Perez-Bermejo, M. (2020). COVID-19: Social irresponsibility of teenagers towards the second wave in Spain. Journal of Epidemiology, 30(10), 483.

Najafimehr, H., Ali, K. M., Safari, S., Yousefifard, M., \& Hosseini, M. (2020). Estimation of basic reproduction number for COVID-19 and the reasons for its differences. International Journal of Clinical Practice, 74(8), 1-2.

National Institute of Health, Colombia (2020). COVID-19 Colombia. Reporte 23-11-2020. https://www. ins.gov.co/Noticias/Paginas/Coronavirus.aspx. Accessed 2 December 2020.

Nguyen, H. T., Do, B. N., Pham, K. M., et al. (2020). Fear of COVID-19 scale-Associations of its scores with health literacy and health-related behaviors among medical students. International Journal of Environmental Research and Public Health, 17(11), 1-14.

Olaimat, A. N., Aolymat, I., Shahbaz, H. M., \& Holley, R. A. (2020). Knowledge and information sources about COVID-19 among university students in Jordan: A cross-sectional study. Frontiers in Public Health, 8, 1-9.

Olum, R., Chekwech, G., Wekha, G., Nassozi, D. R., \& Bongomin, F. (2020). Coronavirus disease-2019: Knowledge, attitude, and practices of health care workers at Makerere university teaching hospitals, Uganda. Frontiers in Public Health, 8, 1-9.

Paakkari, L., \& Okan, O. (2020). COVID-19: Health literacy is an underestimated problem. The Lancet Public Health, 5(5), 249-250.

Palayew, A., Norgaard, O., Safreed-Harmon, K., Andersen, T. H., Rasmussen, L. N., \& Lazarus, J. V. (2020). Pandemic publishing poses a new COVID-19 challenge. Nature Human Behaviour, 4(7), 666-669.

Prather, K. A., Marr, L. C., Schooley, R. T., McDiarmid, M. A., Wilson, M. E., \& Milton, D. K. (2020). Airborne transmission of SARS-CoV-2. Science, 370(6514), 303-304.

Petrosillo, N., Viceconte, G., Ergonul, O., Ippolito, G., \& Petersen, E. (2020). COVID-19, SARS and MERS: are they closely related? Clinical Microbiology and Infection, 26(6), 729-734.

Reiss, M. J. (2020). Science education in the light of COVID-19. The contribution of history, philosophy and sociology of science. Science \& Education, 29(4), 1079-1092.

Reuben, R. C., Danladi, M. M. A., Saleh, D. A., \& Ejembi, P. E. (2020). Knowledge, attitudes and practices towards COVID-19: An epidemiological survey in North-Central Nigeria. Journal of Community Health. https://doi.org/10.1007/s10900-020-00881-1.

Roberts, D. A. (2007). Scientific literacy/science literacy. In S. K. Abell \& N. G. Lederman (Eds.), Handbook of research on science education. (pp. 729-780). Lawrence Erlbaum Associates.

Sahoo, S., Padhy, S. K., Ipsita, J., Mehra, A., \& Grover, S. (2020). Demystifying the myths about COVID19 infection and its societal importance. Asian Journal of Psychiatry, 54, 1-6.

Salman, M., Mustafa, Z. U., Asif, N., Zaidi, H. A., Hussain, K., Shehzadi, N., Khan, T. M., \& Saleem, Z. (2020). Knowledge, attitude and preventive practices related to COVID-19: A cross-sectional study in two Pakistani university populations. Drugs \& Therapy Perspectives, 36(7), 319-325.

Sari, D. K., Amelia, R., Dharmajaya, R., Sari, L. M., \& Fitri, N. K. (2021). Positive correlation between general public knowledge and attitudes regarding COVID-19 outbreak 1 month after first cases reported in Indonesia. Journal of Community Health, 36(7), 319-325.

Saribas, D., \& Çetinkaya, E. (2020). Pre-service teachers' analysis of claims about COVID-19 in an online course. Science \& Education. https://doi.org/10.1007/s11191-020-00181-z.

Seale, H., Heywood, A. E., Leask, J., Sheel, M., Thomas, S., Durrheim, D. N., Bolsewicz, K., \& Kaur, R. (2020). COVID-19 is rapidly changing: Examining public perceptions and behaviors in response to this evolving pandemic. PLoSONE, 15(6), 1-13.

Sentell, T., Vamos, S., \& Okan, O. (2020). Interdisciplinary perspectives on health literacy research around the world: More important than ever in a time of COVID-19. International Journal of Environmental Research and Public Health, 17(9), 1-13.

Sinclair, W. J. (1909). Semmelweis: his life and his doctrine. Manchester University Press.

Thomas, M. S. C., \& Rogers, V. (2020). Education, the science of learning, and the COVID-19 crisis. Prospects, 49(1-2), 87-90.

Thorp, H. H. (2020). Persuasive words are not enough. Science, 368(6498), 1405.

Usman, I. M., Ssempijja, F., Ssebuufu, R., et al. (2020). Community drivers affecting adherence to WHO guidelines against COVID-19 amongst rural Ugandan market vendors. Frontiers in Public Health, 8, 1-13.

Verma, G., Campbell, T., Melville, W., \& Park, B.-Y. (2020). Science teacher education in the times of the COVID-19 pandemic. Journal of Science Teacher Education, 31(5), 483-490. 
Wang, D., Hu, B., Hu, C., et al. (2020). Clinical characteristics of 138 hospitalized patients with 2019 novel coronavirus-infected pneumonia in Wuhan China. JAMA, 323(11), 1061-1069.

Weissleder, R., Lee, H., Ko, J., \& Pittet, M. J. (2020). COVID-19 diagnostics in context. Science Translational Medicine, 12(546), 1-5.

World Health Organization. (1998). Health promotion glossary. World Health Organization.

World Health Organization (2020a). Novel coronavirus(2019-nCoV) situation report - 11. Geneva: World Health Organization. January 31, https://www.who.int/docs/default-source/coronaviruse/situationreports/20200131-sitrep-11-ncov.pdf?sfvrsn=de7c0f7_4. Accessed 4 November July 2020.

World Health Organization (2020b). Coronavirus disease 2019 (COVID-19) situation report - 52. Geneva: World Health Organization. March 12, https://www.who.int/docs/default-source/coronaviruse/situa tion-reports/20200312-sitrep-52-covid-19.pdf?sfvrsn=e2bfc9c0_4. Accessed 4 November 2020.

World Health Organization (2020c). Coronavirus disease 2019 (COVID-19) situation report - 117. Geneva: World Health Organization. May 16, https://www.who.int/docs/default-source/coronaviruse/situationreports/20200516-covid-19-sitrep-117.pdf?sfvrsn=8f562cc_2. Accessed 5 November 2020.

World Health Organization (2020d). Report of the WHO-China joint mission on coronavirus disease 2019 (COVID-19). February 16-24, https://www.who.int/docs/default-source/coronaviruse/who-chinajoint-mission-on-covid-19-final-report.pdf. Accessed 6 November 2020.

World Health Organization (2020e). Transmission of SARS-CoV-2: Implications for infection prevention precautions. https://www.who.int/news-room/commentaries/detail/transmission-of-sars-cov-2-impli cations-for-infection-prevention-precautions. Accessed 6 November 2020.

World Health Organization (2020f). What are the symptoms of COVID-19? https://www.who.int/emerg encies/diseases/novel-coronavirus-2019/question-and-answers-hub/q-a-detail/q-a-coronaviruses. Accessed 6 November 2020.

Yamin, M. (2020). Counting the cost of COVID-19. International Journal of Information Technology, 12(2), 311-317.

Zhong, B.-L., Luo, W., Li, H.-M., Zhang, Q.-Q., Liu, X.-G., Li, W.-T., \& Li, Y. (2020). Knowledge, attitudes, and practices towards COVID-19 among Chinese residents during the rapid rise period of the COVID-19 outbreak: A quick online cross-sectional survey. International Journal of Biological Sciences, 16(10), 1745-1752.

Zhu, X., \& Liu, J. (2020). Education in and after Covid-19: Immediate responses and long-term visions. Postdigital Science and Education, 2(3), 695-699.

Publisher's Note Springer Nature remains neutral with regard to jurisdictional claims in published maps and institutional affiliations.

\section{Authors and Affiliations}

\section{Pablo Antonio Archila ${ }^{1}$ (D) . Giovanna Danies ${ }^{2} \cdot$ Jorge Molina $^{3}$. Anne-Marie Truscott de Mejía ${ }^{4} \cdot$ Silvia Restrepo $^{1}$}

Giovanna Danies

g-danies@uniandes.edu.co

Jorge Molina

jmolina@uniandes.edu.co

Anne-Marie Truscott de Mejía

atruscot@uniandes.edu.co

Silvia Restrepo

srestrep@uniandes.edu.co

1 Vice-Presidency of Research and Creation, Universidad de los Andes, Bogotá, Colombia

2 Department of Design, Universidad de los Andes, Bogotá, Colombia

3 Department of Biological Sciences, Universidad de los Andes, Bogotá, Colombia

4 School of Education, Universidad de los Andes, Bogotá, Colombia 